\title{
JOE'S TASTINGS
}

LyN Chatham

\author{
Malaysian girls with pink hair and cleavage \\ German anaesthetists from Christchurch \\ and grey-haired greeters from Target \\ gather in the houses of Jesus to taste \\ some sacred ladies — not because they all believe \\ but for dark panelled hallways with parquetry \\ floors, angels in oils above softly lit landings \\ and white-skinned Jews in blue-stained glass. \\ And for disciples like Joe in sparkling jacket \\ and bowtie, throwing around metaphors \\ like he's a poet — and for altar boys like Kevin, \\ with his orange freckles and words for sale, \\ playing down that he's a librarian, by day, \\ answering the call for another glass, \\ allowing us that state of grace, until tomorrow.
}

